\title{
Curing Kinetics, Mechanical Properties and Thermomechanical Analysis of Carbon Fiber/epoxy Resin Laminates with Different Ply Orientations
}

Chenglin Zhang

Shandong University of Technology - West Campus: Shandong University of Technology

Guohua Gu

Shandong University of Technology - West Campus: Shandong University of Technology

Shuhua Dong (D 54747302@qq.com )

Shandong University of Technology - West Campus: Shandong University of Technology https://orcid.org/0000-0002-0857-9737

\section{Zhitao Lin}

Shandong University of Technology - West Campus: Shandong University of Technology

\section{Chuncheng Wei}

Shandong University of Technology - West Campus: Shandong University of Technology

Hongsheng Tan

Shandong University of Technology - West Campus: Shandong University of Technology

\section{Research Article}

Keywords: Laminates, Curing kinetics, Dynamic thermomechanical analysis, Mechanical properties

Posted Date: March 3rd, 2021

DOl: https://doi.org/10.21203/rs.3.rs-258456/v1

License: (c) (i) This work is licensed under a Creative Commons Attribution 4.0 International License. Read Full License 
Curing kinetics, mechanical properties and thermomechanical analysis of carbon fiber/epoxy resin laminates with different ply orientations

\begin{abstract}
In this study, the nonisothermal differential scanning calorimetry (DSC) was carried out to evaluate the curing reaction of fiber/epoxy laminates. The optimal curing process of the prepreg was obtained by T- $\beta$ extrapolation method and $n^{\text {th }}$-order reaction curing kinetic equation. The bending strength, impact strength and thermodynamic properties of the composite laminates with different ply orientations were investigated, respectively. The results show that the apparent activation energy and the reaction order of the prepregs are $82.89 \mathrm{~kJ} / \mathrm{mol}$ and 0.92 , respectively. The curing process of carbon fiber/epoxy resin prepreg is $130{ }^{\circ} \mathrm{C}$ $/ 60 \mathrm{~min}+160{ }^{\circ} \mathrm{C} / 30 \mathrm{~min}$. The bending strength of [0] $]_{10}$ laminate is $1948.3 \mathrm{MPa}$, which is 11.8 times higher than that of $[+45 /-45]_{5 \mathrm{~s}}$ laminate, and $96.4 \%$ higher than that of $[0 / 90]_{5 \mathrm{~s}}$ laminate. The impact strength of $[0]_{10}$ laminate is higher than that of $[+45 /-45]_{5 \mathrm{~s}}$ and $[0 / 90]_{5 \mathrm{~s}}$ laminates. The glass transition temperature $\left(T_{\mathrm{g}}\right)$ of the laminates is $142 \sim 146{ }^{\circ} \mathrm{C}$, and the loss factor of [0] $]_{10}$ laminate is significantly higher than that of $[+45 /-45]_{5 \mathrm{~s}}$ and $[0 / 90]_{5 \mathrm{~s}}$ laminates. This research provides a theoretical basis for the further application of prepregs to fiber composite materials.
\end{abstract}

Keywords Laminates $\bullet$ Curing kinetics $\bullet$ Dynamic thermomechanical analysis $\bullet$ Mechanical properties

\title{
1 Introduction
}

With the improvement of the manufacturing technology and the reduction of cost for prepregs, the application and development of laminate composite materials have been greatly promoted in the past few decades. Due to the advantages of high specific strength, high specific modulus, high designability, good fatigue and corrosion resistance, high efficiency of preparation and uniformity and stability of final product quality, carbon fiber/epoxy resin laminates have attracted increasing attention [1-3]. These advanced materials have been widely used in the fields of aerospace, transportation, wind power, marine and shipbuilding industries, which plays an important role in the national defense construction and economic development [4-6].

The application of laminated composites has greatly improved the designability of composite materials. However, the laminates with the different stacking methods show the obvious "layering" and "heterogeneity" in the thickness direction, leading to the coupling of their bending and in-plane characteristics. Moreover, 
due to the distinct anisotropy of the laminates, the properties and research methods of the laminates are different from the traditional materials. Therefore, the performance research of laminates is more complicated than other non-layered materials $[7,8]$.

The degree of crosslinking, curing process and mechanical properties, as coupling results of chemical reaction, heat transfer and product quality, play a decisive role in the comprehensive performance of the composites [9]. Some researches on the curing process and mechanical properties of the laminated composites are mainly focused on the curing kinetics and the stacking methods of the prepregs, respectively, which are not only the key to the success of curing process, but also are the guarantee of products quality $[10,11]$. Wang et al. [12] used the phenomenological autocatalysis model to study the curing kinetics of $\mathrm{GO} /$ waterborne epoxy emulsion composites. On this basis, the optimal curing temperature and time of the system were obtained, which suppressed the thermal shock and improved the mechanical properties of the composites. Xiong et al. [13] studied the curing kinetics of an epoxy curing system by Kissinger and FlynnWall-Ozawa equations. The results showed that the system followed the autocatalytic model, and the $n^{\text {th }}$ order reaction mechanism was dominant. Newcomb et al. [14] used carbon fiber/epoxy resin prepreg as raw material to characterize its gel behavior by small amplitude oscillatory shear, and obtained its curing kinetic parameters by phenomenological model. Subsequently, the curing kinetics, rheological behavior and TTT cure diagram were determined, which provided us a novel research system for the study on curing process of composite materials. Yokozeki et al. [15] observed the cracking behavior of $\left[0^{\circ} / \theta_{n} / 90^{\circ}\right]_{\mathrm{s}}(n=1$ or 2) laminates with $\theta=30,45$ and $60^{\circ}$, and studied the effects of ply thickness and intersection angles of crack layers on crack propagation in adjacent layers. The results showed that the smaller the intersection angles of crack layers were, and the thinner the thickness of $\theta$ layers was, the higher the sensitivity of $\theta$ layers to high-density matrix microcracks got. Sas et al. [16] confirmed that the stacking orders and angles of unidirectional fabrics have a significant effect on the permeability of resin in the direction of fabric thickness through the combination of numerical simulation and experimental measurement. These researchers demonstrate that it is of great significance to study the curing process and lay-up methods of prepregs to improve the comprehensive properties of new materials, which will promote the manufacture of advanced composite products. However, most researchers pay more attention to the curing kinetics of resin or the influence of lamination methods on the mechanical properties of laminates, and have not yet combined both of them to form a scientific and complete system.

In this paper, the $n^{\text {th }}$-order reaction curing kinetics of carbon fiber/epoxy resin prepreg was studied by 
phenomenological method, and then the optimum curing process of the prepreg were determined. The laminates of $[0]_{10},[+45 /-45]_{5 \mathrm{~s}}$ and $[0 / 90]_{5 \mathrm{~s}}$ were prepared by compression molding method, and the thermodynamic and mechanical properties of the composites were studied, which will provide a theoretical basis for the research and enhancement of high value-added composite products.

\section{Experimental}

\subsection{Material}

USN 02000 carbon fiber/epoxy resin prepregs were purchased from Weihai Guangwei Composites Co., Ltd. (the epoxy resin content was $30 \mathrm{wt} \%, 7901$ model). The fiber (T300) was manufactured from Toray Industries Inc..

\subsection{Preparation of composite laminates}

In the optimal range of curing temperature, carbon fiber/epoxy resin laminates of $[0]_{10},[+45 /-45]_{5 \mathrm{~s}}$ and $[0 / 90]_{5 \mathrm{~s}}$ were prepared through compression molding process by flat vulcanizing machine. The standard samples were made by universal sample preparation machine.

\subsection{Characterization}

DSC curves of non-isothermal tests were obtained by differential scanning calorimeter (DSC, Q2000, TA Instruments Company, USA). The test temperature was in the range of $40 \sim 300{ }^{\circ} \mathrm{C}$. All the DSC runs were carried out under $\mathrm{N}_{2}$ atmosphere and analyzed dynamically with heating rates at 5, 10, 15 and $20{ }^{\circ} \mathrm{C} / \mathrm{min}$, respectively. The morphology of the fractured surface was analyzed by a field emission scanning electron microscope (quanta 250, USA). The bending strength of composite laminates was tested in a three-point bend set-up at a strain rate of $10 \mathrm{~mm} / \mathrm{min}$ by electronic universal testing machine (Instron 5969, USA). The size of standard samples was about $80 \times 10 \times 2 \mathrm{~mm}$, and 5 of them were tested every time at least. The impact strength of composite laminates was tested by using electronic impact tester (XJU-5.5J, Beijing Jinsheng testing instrument Co., Ltd). The impact energy was set to $5.5 \mathrm{~J}$. The standard samples for test were prepared with dimensions of $80 \times 10 \times 2 \mathrm{~mm}$, and 5 of them were tested every time at least. DMA test of the laminates was carried out by dynamic mechanical analysis (DMA, Q800, USA) in a single cantilever bending mode. The size of standard samples was $35 \times 10 \times 2 \mathrm{~mm}$. The test frequency was $1 \mathrm{~Hz}$, the heating rate was $5{ }^{\circ} \mathrm{C} / \mathrm{min}$, and the temperature was in the range of $0 \sim 250{ }^{\circ} \mathrm{C}$. 


\section{Results and discussion}

\subsection{DSC analysis}

The DSC curves of carbon fiber/epoxy resin prepreg at different heating rates are shown in Fig. 1. It can be seen from Fig. 1 that all of the exothermic peaks at different heating rates are distinct and single, indicating that the curing reaction of the prepregs at different heating rates belongs to a single reaction step. With the increase of heating rates, the exothermic peak moves towards the high temperature direction. This phenomenon can be attributed to the thermal lag effect, that is, some monomers or other reaction components do not react or spread into the gel system in time within a specific range of temperature $[17,18]$. The starting temperature $\left(T_{\mathrm{i}}\right)$, the peak temperature $\left(T_{\mathrm{p}}\right)$, the ending temperature $\left(T_{\mathrm{f}}\right)$ and the reaction enthalpy $\left(\Delta H_{0}\right)$ of the curing reaction can be obtained from the DSC curves (Table 1). From table 1, it can be seen that the characteristic temperatures have a moving trend to the high temperature region with the increase of heating rates.

\section{$<$ Fig. 1 $>$ \\ $<$ Fig. 2> \\ $<$ Table 1 $>$}

Using the phenomenological method, the relationship between the curing degree and enthalpy can be obtained by DSC curves [12]:

$$
\alpha=\frac{H(t)}{\Delta H_{0}}
$$

where $H(\mathrm{t})$ is the heat of reaction at the time $t$, and $\Delta H_{0}$ is the total heat of curing reaction. Fig. 2 shows the relationship between curing degree of the prepregs and temperature at different heating rates. It can be seen that all curves firstly increase slowly, then sharply increase and subsequently level off. Meanwhile, the curve moves towards high temperature region with the increase of heating rate. The temperature to achieve the same curing degree is higher at the high heating rate than that at the low heating rate. This is mainly due to the increase of reaction speed and viscosity of the system, leading to some monomers have no enough time to react completely or spread into the gel system in time [13].

\subsection{Analysis of kinetic parameters of non-isothermal curing reaction}

The pre-exponential factor $(A)$, the apparent activation energy $\left(E_{\mathrm{a}}\right)$ and the reaction order $(n)$ are three important guiding parameters for the formulation of curing process and the selection of curing schemes. 
The apparent activation energy $\left(E_{\mathrm{a}}\right)$ is an important parameter to evaluate curing reaction. It refers to the required energy for an effective collision of molecules when participating in a chemical reaction. The larger the $E_{\mathrm{a}}$ is, the more difficult the curing reaction becomes. The pre-exponential factor $(A)$ is a parameter of the effective collision of molecules in a reaction. The reaction order $(n)$ reflects the complexity of a curing reaction. The larger the value of $n$ is, the more complicated the curing reaction gets [19].

The basic form of the $n^{\text {th }}$-order reaction kinetic model as follows [10]:

$$
\frac{\mathrm{d} \alpha}{\mathrm{d} t}=A \exp \left(\frac{-E_{a}}{R T}\right) \cdot(1-\alpha)^{n}
$$

The apparent activation energy $E_{\mathrm{a}}$ and the pre-exponential factor $A$ can be obtained by Kissinger equation [13]:

$$
\ln \left(\frac{\beta}{T_{p}^{2}}\right)=\ln \left(\frac{A R}{E_{a}}\right)-\frac{E_{a}}{R T_{p}}
$$

The Kissinger equation shows that the activation energy $E_{\mathrm{a}}$ and the pre-exponential factor $A$ can be obtained from the slope and intercept, respectively, when plotted by $\ln \left(\beta / T_{\mathrm{p}}^{2}\right)$ to $1 / T_{\mathrm{p}}$ and fitted linearly. The plots of $\ln \left(\beta / T_{\mathrm{p}}^{2}\right)$ versus $1 / T_{\mathrm{p}}$ are shown in Fig. 3. As a result, the slope $k$ is -9.97 , the intercept $b$ is 13.34 , the Pearson correlation coefficient is -0.998 , and $\mathrm{R}^{2}$ is 0.996 , which proves that the best-fitted straight line to the model and the obtained data has a high reliability. When the fitting results are brought into the Kissinger equation, $E_{\mathrm{a}}$ and $A$ are calculated as $82.89 \mathrm{~kJ} / \mathrm{mol}$ and $6.21 \times 10^{9} \mathrm{~min}^{-1}$, respectively.

The reaction order $(n)$ can be obtained by the Crane equation [11]:

$$
\frac{\mathrm{d}(\ln \beta)}{\mathrm{d}\left(1 / T_{\mathrm{p}}\right)} \approx-\frac{E_{a}}{n R}
$$

The Crane equation shows that the reaction order can be obtained by plotting $\ln \beta$ against $1 / T_{\mathrm{p}}$ and performing a linear fit. Fig. 4 shows that the slope $k=-E_{\mathrm{a}} / n \mathrm{R}=-10.81$, the Pearson correlation coefficient is -0.98 , and $\mathrm{R}^{2}$ is 0.996 , which indicate that the curve has a good linear relationship. And we can get that the reaction order $n$ is 0.92 when $E_{\mathrm{a}}$ is introduced into the Eq. (4).

$<$ Fig. 3>

$<$ Fig. 4 $>$

The $n^{\text {th }}$-order reaction curing kinetic equation of the prepreg can be obtained by bringing the apparent activation energy, the pre-exponential factor and the reaction order into the Eq. (2): 


$$
\frac{\mathrm{d} \alpha}{\mathrm{d} t}=6.21 \times 10^{9} \exp \left(\frac{-82890}{R T}\right) \cdot(1-\alpha)^{0.92}
$$

The relationship among the curing rates, temperature and time can be obtained by integrating Eq. (5):

$$
\alpha(t)=1-\left[1-5.0 \times 10^{8} \exp \left(-\frac{1.0 \times 10^{4}}{T}\right) \cdot t\right]^{12.5}
$$

\subsection{Determination of the curing process}

The T- $\beta$ extrapolation method is usually used to determine the optimum range of curing temperature in practical production. This method is that the characteristic parameters $\left(T_{\mathrm{i}}, T_{\mathrm{p}}, T_{\mathrm{f}}\right)$ through the DSC scanning at different heating rates are plotted against the heating rates, and a linear fit is performed. When extrapolated to $\beta=0$, three extrapolation temperatures, namely theoretical gel temperature $\left(T^{*}{ }_{\mathrm{i}}\right)$, theoretical curing temperature $\left(T^{*}{ }_{\mathrm{p}}\right)$ and theoretical post-processing temperature $\left(T^{*}{ }_{\mathrm{f}}\right)$, are obtained to determine the range of curing temperature. Fig. 5 is the extrapolation curves of the curing temperatures. The Pearson correlation coefficients of the three fitting curves $\left(T_{\mathrm{i}}, T_{\mathrm{p}}, T_{\mathrm{f}}\right)$ are $0.94,0.97$ and 0.96 , respectively, and the corresponding $\mathrm{R}^{2}$ are $0.89,0.93$ and 0.92 , which prove that all the three fitting curves have a good linear relationship. The extrapolation temperatures $\left(T^{*}\right.$ i, $T^{*}$ p, $T^{*}$ f) of the prepregs are 114.6, 140.7 and $174.2{ }^{\circ} \mathrm{C}$, respectively, when the three fitted regression lines are extrapolated to $\beta=0$. Generally, if the two-stage curing process was selected for curing epoxy resin, the process temperatures of each stage are separately selected in the ranges of $\left[T^{*}{ }_{\mathrm{i}}, T_{\mathrm{p}}^{*}\right]$ and $\left[T_{\mathrm{p}}^{*}, T_{\mathrm{f}}^{*}\right][12]$. In order to get the curing process of the prepreg accurately, the function relationship between the curing degree and time of the prepregs at different temperatures is shown in Fig. 6. It can be seen that the curing degree of the prepregs increases as the temperature increases, and the higher the processing temperature gets, the faster the curing becomes. The curing degree of the prepregs is in a quite low level when the temperature is lower than the theoretical gel temperature, however, the curing degree rapidly increases when the temperature becomes higher than that temperature. The curing degree is close to 1 when the temperature is $130{ }^{\circ} \mathrm{C}$ for 60 minutes, and the time of complete cure is shortened with the increase of temperature. It only takes about 20 minutes that the curing degree approaches to 1 when the temperature reaches $160{ }^{\circ} \mathrm{C}$. As a result, the curing process of the prepreg was set as $130{ }^{\circ} \mathrm{C} / 60 \mathrm{~min}+160^{\circ} \mathrm{C} / 30 \mathrm{~min}$ (Fig. 7). 


\subsection{Mechanical properties analysis}

Fig. 8 shows the bending strength of carbon fiber/epoxy resin composite laminates. The bending strength of [0 $]_{10}$ laminate is $1948.3 \mathrm{MPa}$, which is $96.4 \%$ higher than that of [0/90 $]_{5 \mathrm{~s}}$ laminate, and 11.8 times higher than that of $[+45 /-45]_{5 s}$ laminate. This can be attributed to the difference of the ply angles. Under subjected to the bending load, the upper surface of the central plane of the specimen is under pressure, while the lower surface is under tension. The $90^{\circ}$ fibers are easy to be torn along the fibers when they suffered from the bending load. Under the action of stress, the $90^{\circ}$ plies cracks laterally and suffer from internal shear failure, while in the direction of $\pm 45^{\circ}$ fibers, the resin matrix and the fibers split, and the cracks first appeared in the matrix, then continuously propagated in and between layers along the direction of $\pm 45^{\circ}$ fibers. The $0^{\circ}$ fibers are the main load-bearing layer, so the [0 $]_{10}$ laminate has the highest bending strength. The orientation angles of the fibers have an important effect on the distribution of the load between the fibers and the matrix.

$<$ Fig. 8>

Fig. 9 shows the impact strength of the composite laminates. The impact strength of $[0]_{10}$ laminate is $195.3 \mathrm{~kJ} / \mathrm{mol}$, which is $24.5 \%$ higher than that of $[+45 /-45]_{5 \mathrm{~s}}$ laminate, and 1.4 times higher than that of $[0 / 90]_{5 s}$ laminate. For $[0]_{10}$ laminate, the matrix is firstly deformed until cracking when the impact direction is perpendicular to the fiber. The absorption energy of crack propagation is high due to the hindrance of the fibers, and the interfacial bond strength between the fibers and matrix is well. For $[+45 /-45]_{5 s}$ laminate, the interlaminar shear stress occurs in each layer of laminate and the interface debonds during impact, which leads to stress concentration and thus the impact strength is reduced. For $90^{\circ}$ direction of $[0 / 90]_{5 \mathrm{~s}}$ laminate, the cracking direction is parallel to the fiber direction. The transverse fibers can't exert an enhancing effect. The $90^{\circ}$ fibers direction laminate begins to break at a lower stress level because the impact direction is parallel to the $90^{\circ}$ fibers direction. The fibers debond and interface layers separate, resulting in the reduction of the impact strength [20,21].

$<$ Fig. 9>

Fig. 10 is the photographs of the surface cracks after bending test of the composite laminates. Under the bending load, the crack propagation direction of $[0]_{10}$ laminate is perpendicular to that of the length of samples. The crack of $[+45 /-45]_{5 s}$ laminate spread along $+45^{\circ} /-45^{\circ}$ direction. The SEM photos of fractured surface with different scanning magnification in impact test of $[0]_{10}$ laminate is shown in Fig. 11. The 
parallel fibers bundles with different lengths are broken, accompanied by the matrix crack and fibers pullout. Few holes appear in the fracture after fibers debonding. A small amount of resin is adhered to the surface of fibers, indicating that the interface compatibility between the fibers and resin is well, so the interface bonding strength of the specimen is high. The impact load firstly passes through the matrix to the fibers, the interface acts as a transfer load, and the failure modes of the composite laminates are mainly fibers breakage, fibers pull-out and matrix failure in the process of impact.

$<$ Fig. 10 $>$

$<$ Fig. 11 $>$

\subsection{DMA analysis}

Fig. 12 is the storage modulus curves of the carbon fiber/epoxy resin $[0]_{10},[ \pm 45]_{5 \mathrm{~s}}$ and $[0 / 90]_{5 \mathrm{~s}}$ laminates. The storage modulus increases with the increase of ply angles, which can be attributed that the formation of more dense fiber network with the increase of prepreg stacking angle. The segment and end groups movement become difficult due to the confinement effect of the structure, and more energy is needed to support the movement of the units. In addition, at a lower temperature $\left(<T_{\mathrm{g}}\right)$, the storage modulus of the laminates with different ply angles is relatively high. This is mainly because that the molecular chain does not move or only undergoes "secondary transformation" below the glass transition temperature $T_{\mathrm{g}}$. When the composites are subjected to external forces, the energy will be stored in the form of potential energy. The laminates behave as an elastic material. In the stage of $0<T<T_{\mathrm{g}}$, the materials are in the glass state where the storage modulus gradually decreases, and the loss modulus increases gradually with the increase of temperature. This is because the molecular segments change from a frozen state to a moving state with the increase of the temperature. Most of the energy is converted from mechanical energy to thermal energy, and dissipated in the form of exotherm. Thereby, the storage energy of laminates rapidly decreases and the energy consumption increases rapidly [22].

Fig. 13 is the loss factor curves of the laminates. The loss factor $\tan \delta$ is the ratio of the loss modulus to the storage modulus of the material, which reflects the internal friction of the material during the movement of the chain [23]. The loss factor of the laminates decreases with the increase of ply angles, suggesting that the internal friction of the segment movement of $[0]_{10}$ laminate is greater than that of the laminates of $[ \pm 45]_{5 \mathrm{~s}}$ and $[0 / 90]_{5 \mathrm{~s}}$. This phenomenon can be attributed to the confinement effect of dense fiber network [24]. This structure acts as a barrier within the composites, thus reducing the free volume of the chain 
segment, which reduces the internal friction caused by the chain segment motion, leading to the reduction of the loss factor. It can also be seen that the peak of the $\tan \delta$ corresponds to the curve where the storage modulus drops the fastest. The glass transition temperature $T_{\mathrm{g}}$ of the laminates can be obtained from the peak temperatures of $\tan \delta$ curves, which is an important parameter that affects the performance and process properties of the materials [13]. $T_{\mathrm{g}}$ of $[0]_{10},[ \pm 45]_{5 \mathrm{~s}}$ and $[0 / 90]_{5 \mathrm{~s}}$ is 142,146 and $143{ }^{\circ} \mathrm{C}$, respectively.

$<$ Fig. 12>

$<$ Fig. 13>

\section{Conclusion}

In this paper, the carbon fiber/epoxy resin prepreg was tested by DSC, and then the phenomenological $n^{\text {th }}$ order reaction curing kinetic model of the prepreg was established by Kissinger and Crane equations. On this basis, the optimum curing process of the prepreg was obtained, and the laminates of $[0]_{10},[+45 /-45]_{5 \mathrm{~s}}$ and $[0 / 90]_{5 \mathrm{~s}}$ were prepared by compression molding method. In addition, in order to explore the effect of ply parameters on the mechanical properties of the laminates, the thermodynamic and mechanical properties of the composites were investigated. The results show that the apparent activation energy and the reaction order of the prepregs are $82.89 \mathrm{~kJ} / \mathrm{mol}$ and 0.92 , respectively, and the curing process of the prepreg is set as $130^{\circ} \mathrm{C} / 60 \mathrm{~min}+160^{\circ} \mathrm{C} / 30 \mathrm{~min}$. The $T_{\mathrm{g}}$ of the laminates is $142-146^{\circ} \mathrm{C}$, and the loss factor of [0] $]_{10}$ laminate is significantly higher than that of $[+45 /-45]_{5 \mathrm{~s}}$ and $[0 / 90]_{5 \mathrm{~s}}$ laminates. The bending strength of $[0]_{10}$ laminate is $1948.3 \mathrm{MPa}$, which is 11.8 times higher than that of $[+45 /-45]_{5 \mathrm{~s}}$ laminate, and $96.4 \%$ higher than that of $[0 / 90]_{5 \mathrm{~s}}$ laminate. The impact strength of $[0]_{10}$ laminate is higher than that of $[+45 /-45]_{5 \mathrm{~s}}$ and $[0 / 90]_{5 \mathrm{~s}}$ laminates. The great differences in the mechanical properties of the laminates are mainly due to the different amounts of $0^{\circ}$ fibers, which leads to the different bearing and deformation capacity of the laminates under external force.

\section{Acknowledgements}

This work was supported by the Natural Science Foundation of Shandong Province (ZR2020QE075), the Shandong Province key research and development projects (2019JMRH0213) and the Zibo City \& School Integrated Development Plan Project (2018ZBXC005).

\section{Compliance with ethical standards}

\section{Conflict of interest}


The authors declare that they have no conflict of interest.

\section{References}

1. C. Qian, W.K. Shi, Z.Y. Chen, S.X. Yang, Q.Q. Song, Compos. Struct. 168, 40 (2017) https: //doi.org/10.1016/j.compstruct.2017.02.035

2. E. Alcudia-Zacarías, A. Abúndez-Pliego, J. Mayén, J. Colín-Ocampo, A. Blanco-Ortega, W.M. Alcocer-Rosado, Appl. Compos. Mater. 27, 895 (2020) https://doi.org/10.1007/s10443-020-09839-X

3. S. Sprenger, M.H. Kothmann, V. Altstaedt, Compos. Sci. Technol. 105, 86 (2014) https://doi.o rg/10.1016/j.compscitech.2014.10.003

4. I. Rajendran, S. Vijayarangan, Comput. Struct. 79, 1121 (2001) https://doi.org/10.1016/S00457949(00)00174-7

5. M. Kumar, J.S. Saini, H. Bhunia, S.R. Chowdhury, Appl. Compos. Mater (2021) https://doi.or g/10.1007/s10443-020-09864-w

6. X.M. Yuan, B. Zhu, X. Cai, J.J. Liu, K. Qiao, J.W. Yu, Appl. Surf. Sci. 401, 414 (2017) https://doi.org/10.1016/j.apsusc.2016.12.234

7. D.W. Park, G.H. Oh, H.S. Kim, Compos. B Eng. 177, 107385 (2019) https://doi.org/10.1016/j. compositesb.2019.107385

8. P. Qu, Y. Wan, C.J. Bao, Q. Sun, G.Q. Fang, J. Takahashi, Compos. Struct. 201, 857 (2018) https://doi.org/10.1016/j.compstruct.2018.06.110

9. Y.F. Chen, 'Y.Z. Wu, C.B. Geng, 'Z.G. Li, G.Q. Dai, W.W. Cui, J. Inorg. Organomet. Polym. Mater. 30, 1735 (2020) https://doi.org/10.1007/s10904-019-01290-1

10. L. Zhao, X. Hu, Polymer 48, 6125 (2007) https://doi.org/10.1016/j.polymer.2007.07.067

11. F. Ferdosian, Y.S. Zhang, Z.S. Yuan, M. Anderson, C.B. Xu, Eur. Polym. J. 82, 153 (2016) https://doi.org/10.1016/j.eurpolymj.2016.07.014

12. Z.W. Wang, L.J. Liu, J. Zhang, L.Y. Cao, H.X. Dong, C.H. Zhang, X. Xu, M.X. Zhu, J.Q. Li, Thermochim. Acta 672, 60 (2019) https://doi.org/10.1016/j.tca.2018.12.016

13. X.H. Xiong, X.C. Guo, R. Ren, L. Zhou, P. Chen, Polym. Test 77, 105917 (2019) https://doi. org/10.1016/j.polymertesting.2019.105917

14. B.A. Newcomb, Polym. Test 77, 105859 (2019) https://doi.org/10.1016/j.polymertesting.2019.04.006 
15. T. Yokozeki, T. Aoki, T. Ogasawara, T. Ishikawa, Compos. Part A Appl. Sci. Manuf. 36, 1229 (2005) https://doi.org/10.1016/j.compositesa.2005.02.002

16. H.S. Sas, E.B. Wurtzel, P. Simacek, Compos. Sci. Technol. 96, 116 (2014) https://doi.org/10.1 016/j.compscitech.2014.03.007

17. M. Zolghadr, M.J. Zohuriaan-Mehr, A. Shakeri, A. Salimi, Thermochim. Acta 673, 147 (2019) https://doi.org/10.1016/j.tca.2019.01.025

18. H. Yeo, Polymer 168, 209 (2019) https://doi.org/10.1016/j.polymer.2019.02.058

19. S. Kumar, S.K. Samal, S. Mohanty, S.K. Nayak, J. Therm. Anal. Calorim. 137, 1567 (2019) https://doi.org/10.1007/s10973-019-08080-4

20. K.B. Katnam, H. Dalfi, P. Potluri, Compos. Struct. 225, 111083 (2019) https://doi.org/10.1016/ j.compstruct.2019.111083

21. C.G. Wu, K. Yang, Y.Z. Gu, J. Xu, R.O. Ritchie, J. Guan, Compos. Part A Appl. Sci. Manuf. 117, 357 (2019) https://doi.org/10.1016/j.compositesa.2018.12.003

22. R. Mishra, J. Wiener, J. Militky, M. Petru, B. Tomkova, J. Novotna, Fiber. Polym. 21, 619 (2020) https://doi.org/10.1007/s12221-020-9804-0

23. B. Brylka, M. Schemmann, J. Wood, T. Böhlke, Polym. Test 66, 296 (2018) https://doi.org/1 0.1016/j.polymertesting.2017.12.025

24. J. Wie, M. Kim, J. Kim, Appl. Surf. Sci. 529, 147091 (2020) https://doi.org/10.1016/j.apsusc. 2020.147091 


\section{Figure and table captions}

Fig. 1 DSC curves of the prepregs at different heating rates

Fig. 2 Curves of curing degree-temperatures

Table 1 DSC scanning characteristic temperatures of the prepregs at different heating rates

Fig. 3 Fitting curve of the apparent activation energy and pre-exponential factor

Fig. 4 Fitting curve of the reaction order

Fig. 5 Extrapolation curves of the curing temperatures

Fig. 6 Curves of curing degree and time at different temperatures

Fig. 7 Curing process of the prepregs

Fig. 8 Bending strength of the composite laminates

Fig. 9 Impact strength of the composite laminates

Fig. 10 Surface cracks in bending test of laminates (a) $[0]_{10}$; (b) $[+45 /-45]_{5 \mathrm{~s}}$

Fig. 11 SEM of fractured surface in impact test of $[0]_{10}$ laminate (a) $500 \times$; (b) $2000 \times$

Fig. 12 Storage modulus curves of the laminates

Fig. 13 Loss factor curves of the laminates 


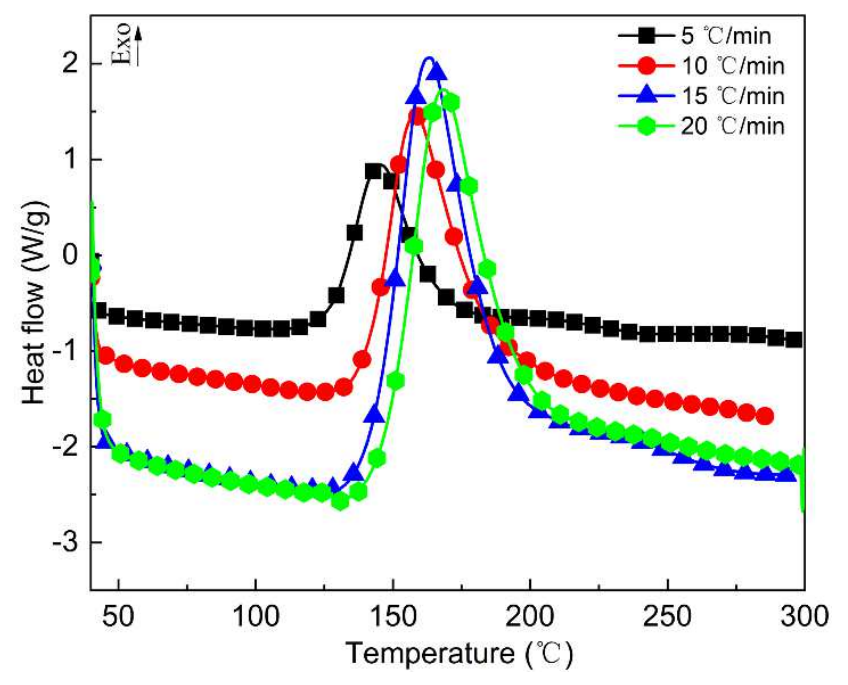

Fig. 1 DSC curves of the prepregs at different heating rates

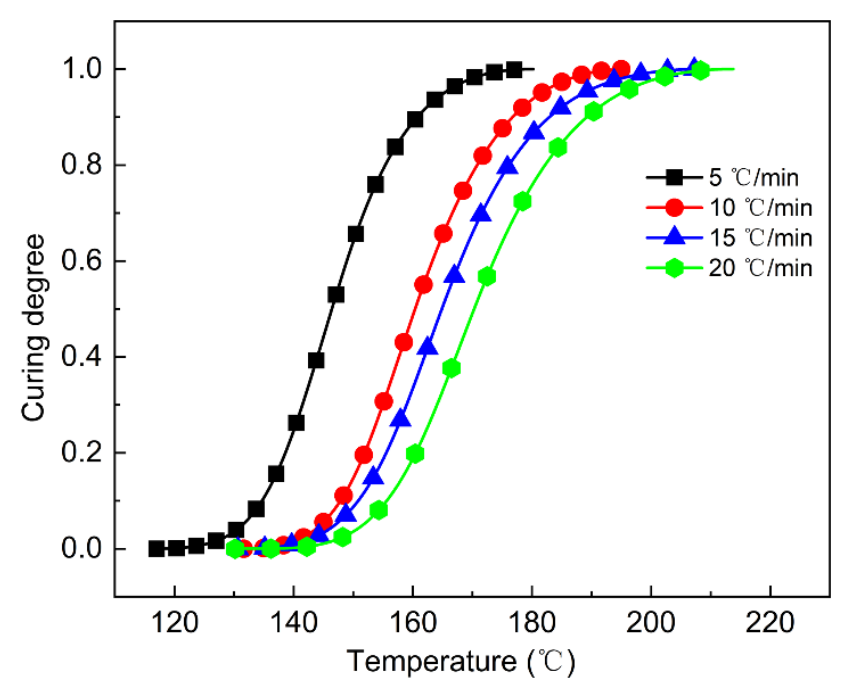

Fig. 2 Curves of curing degree-temperatures 


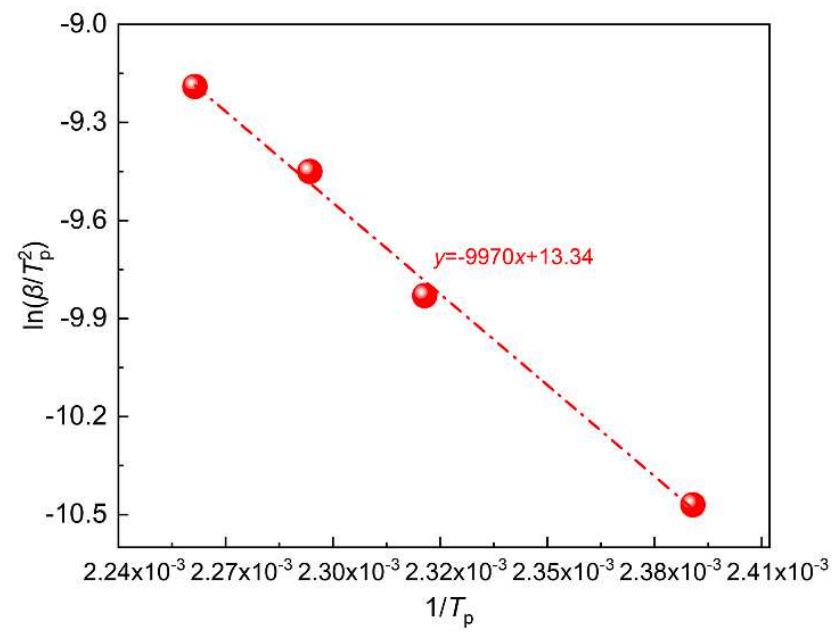

Fig. 3 Fitting curve of the apparent activation energy and pre-exponential factor

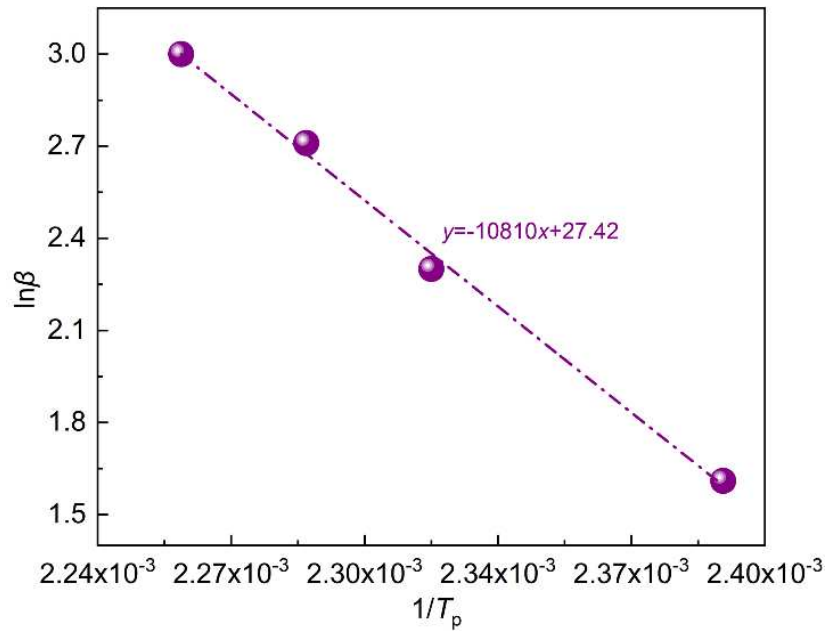

Fig. 4 Fitting curve of the reaction order 


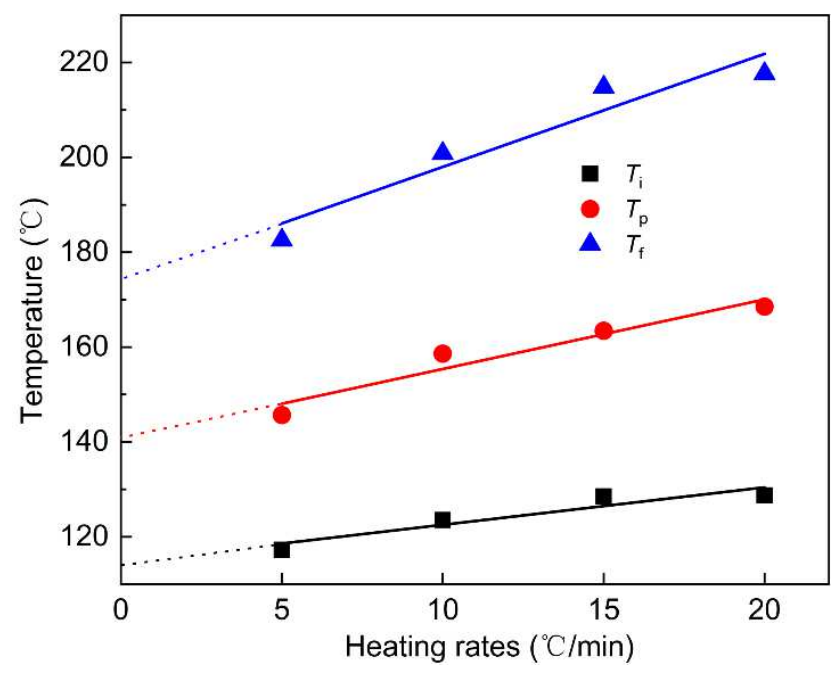

Fig. 5 Extrapolation curves of the curing temperatures

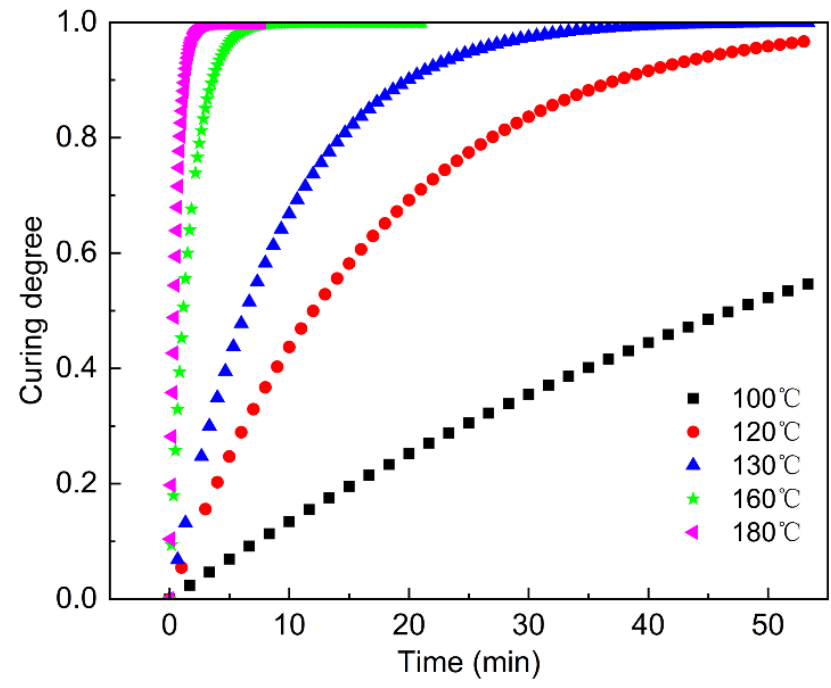

Fig. 6 Curves of curing degree and time at different temperatures 


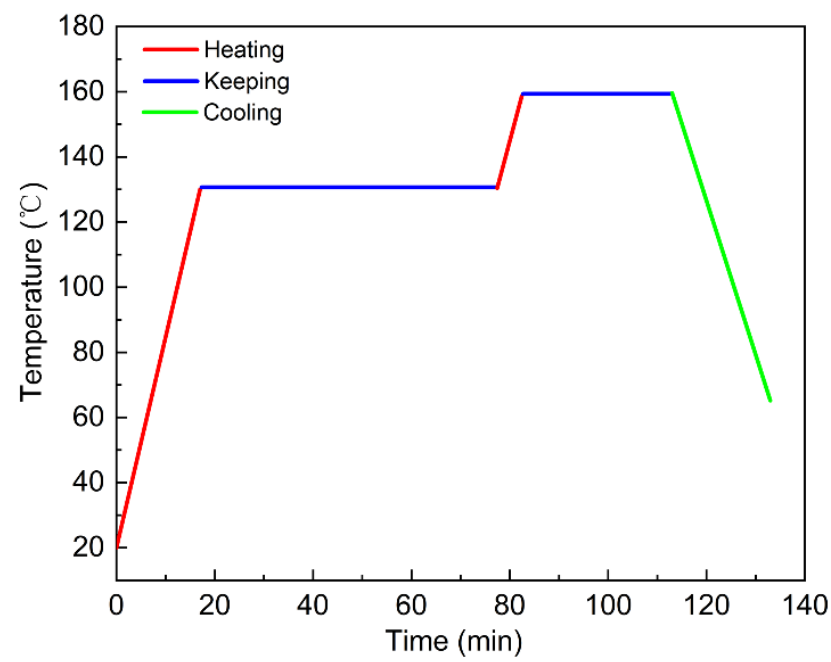

Fig. 7 Curing process of the prepregs

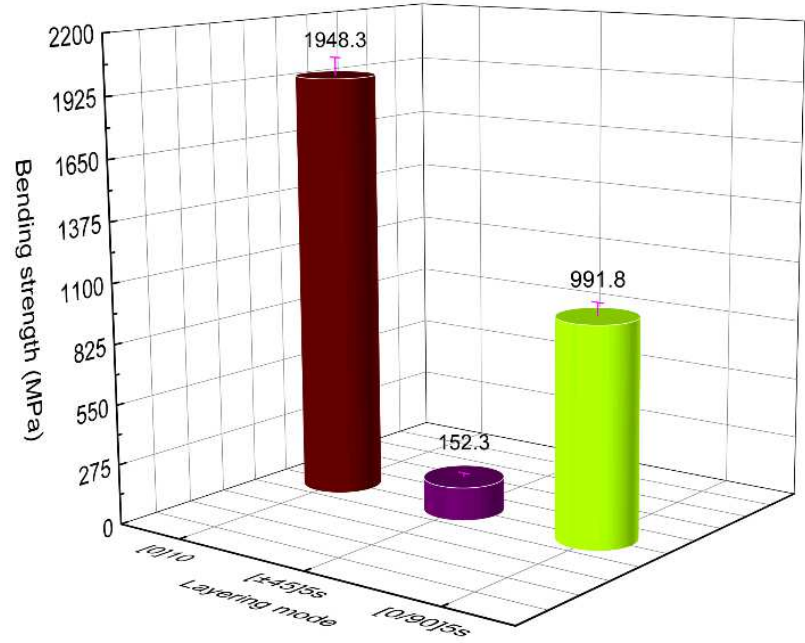

Fig. 8 Bending strength of the composite laminates 


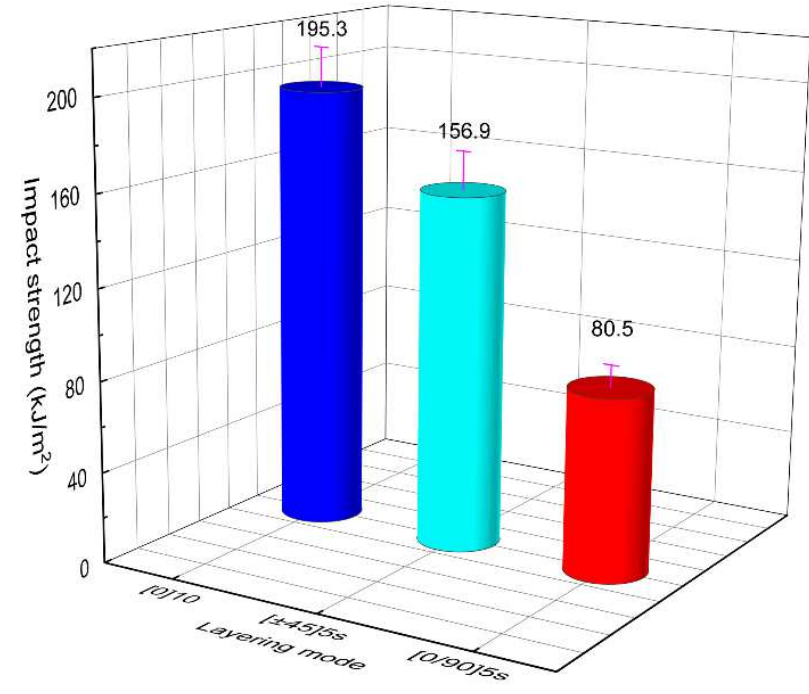

Fig. 9 Impact strength of the composite laminates
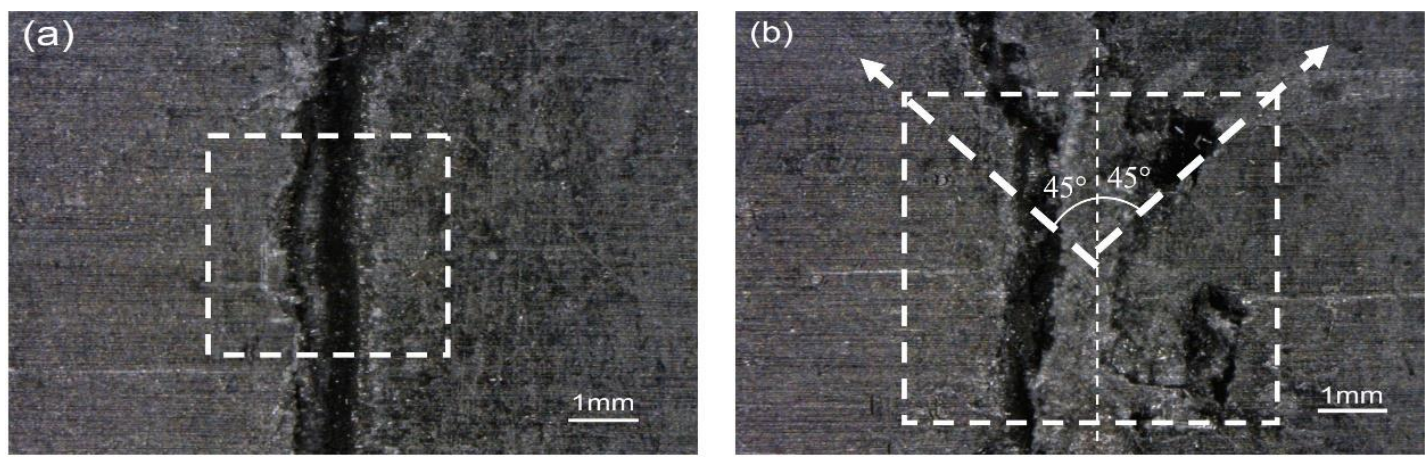

Fig. 10 Surface cracks in bending test of laminates (a) $[0]_{10}$; (b) $[+45 /-45]_{5 \mathrm{~s}}$ 

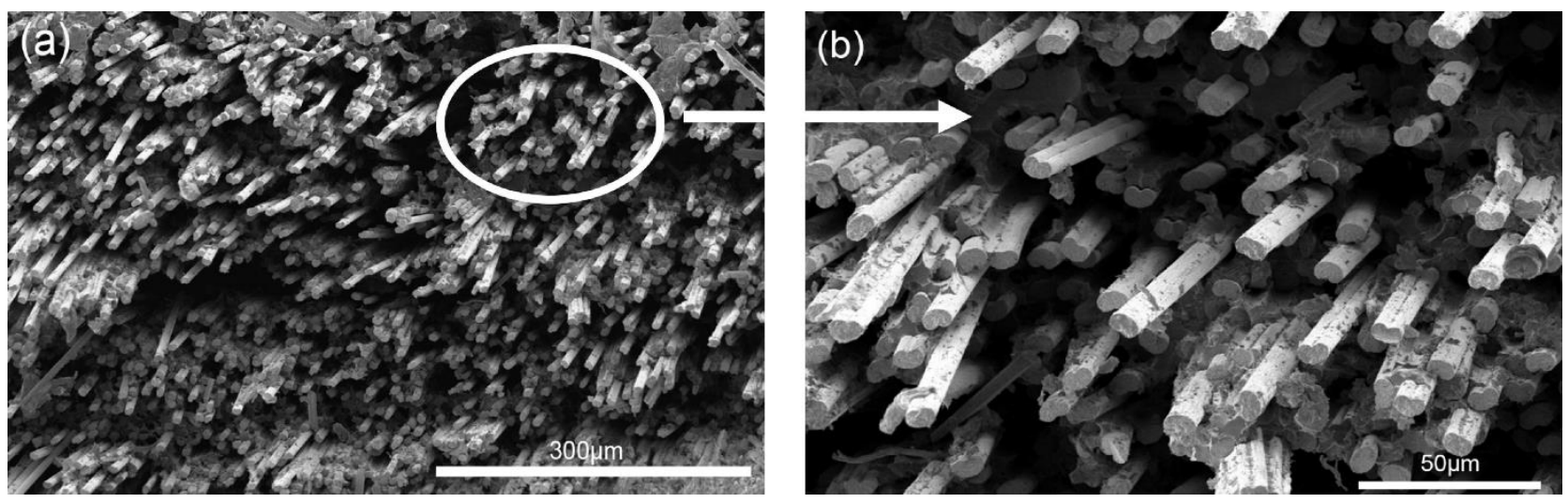

Fig. 11 SEM of fractured surface in impact test of [0 $]_{10}$ laminate (a) $500 \times$; (b) $2000 \times$

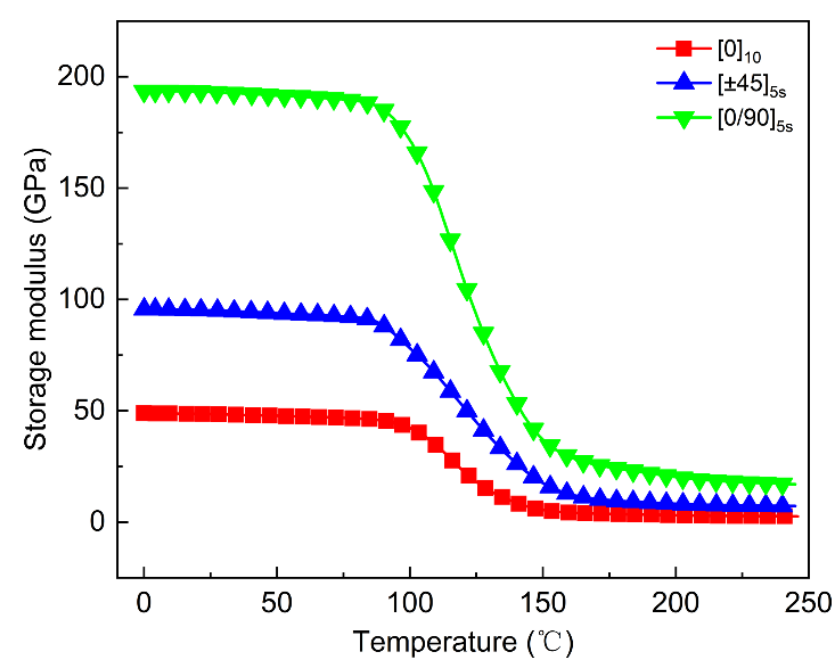

Fig. 12 Storage modulus curves of the laminates

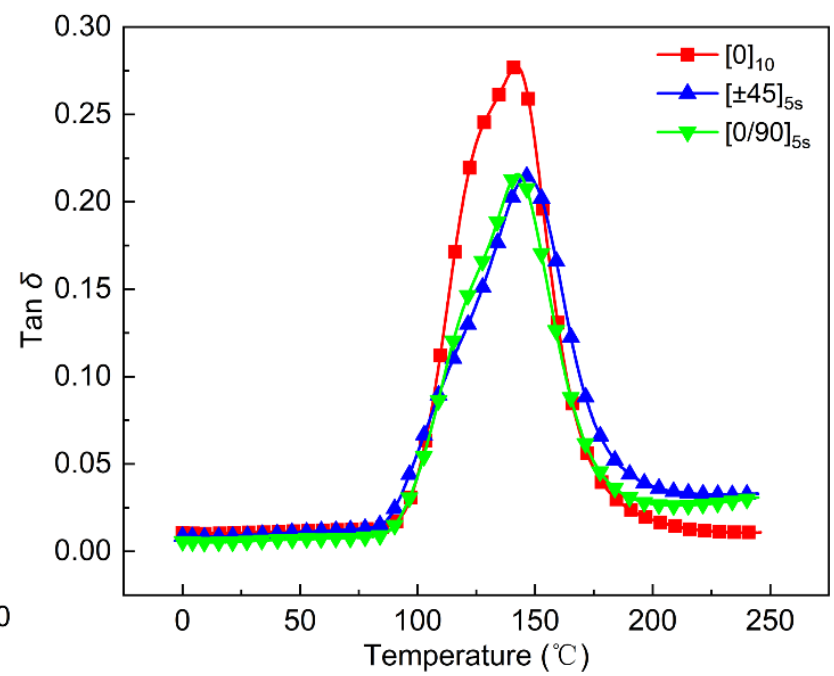

Fig. 13 Loss factor curves of the laminates 
Figures

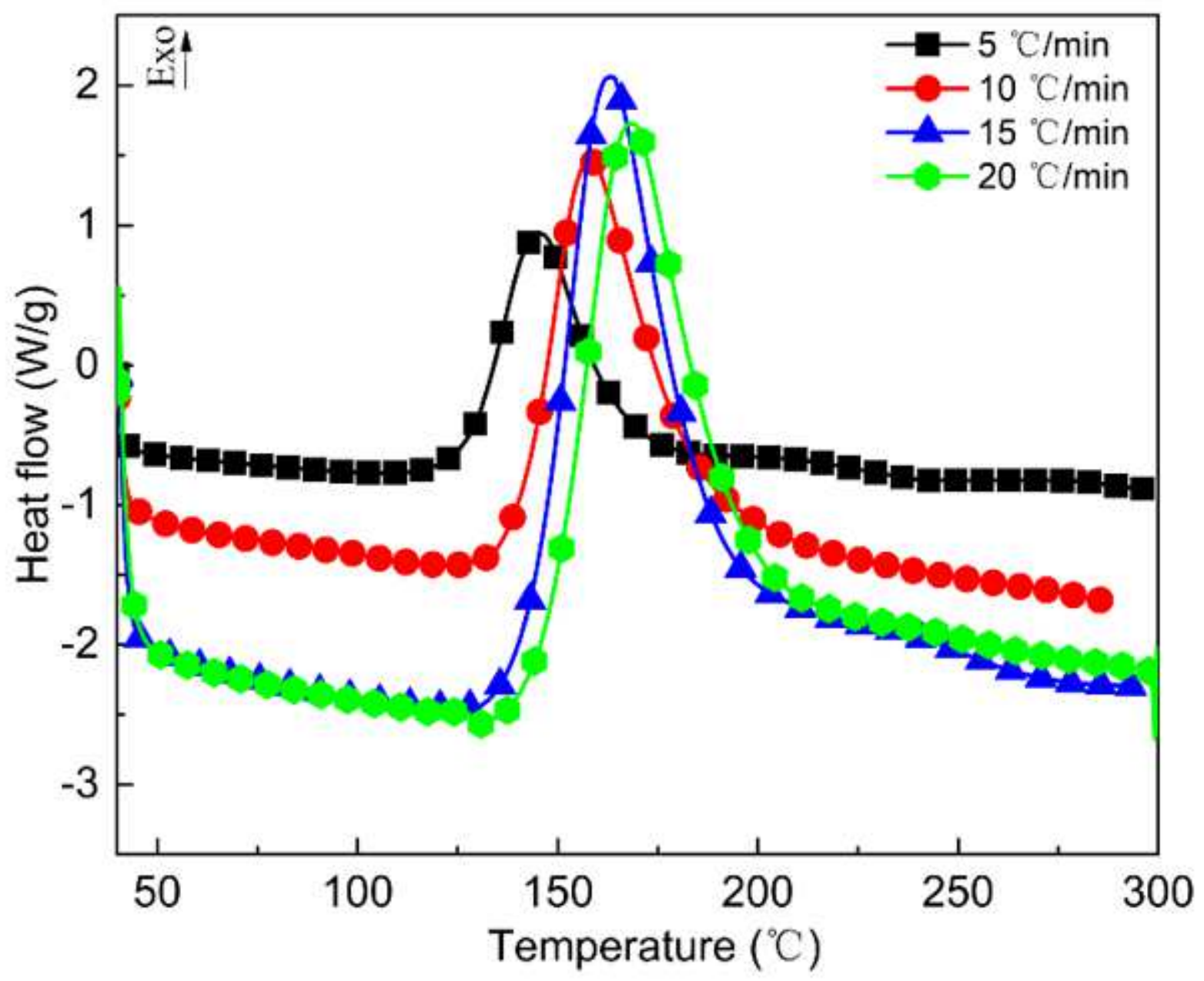

Figure 1

DSC curves of the prepregs at different heating rates 


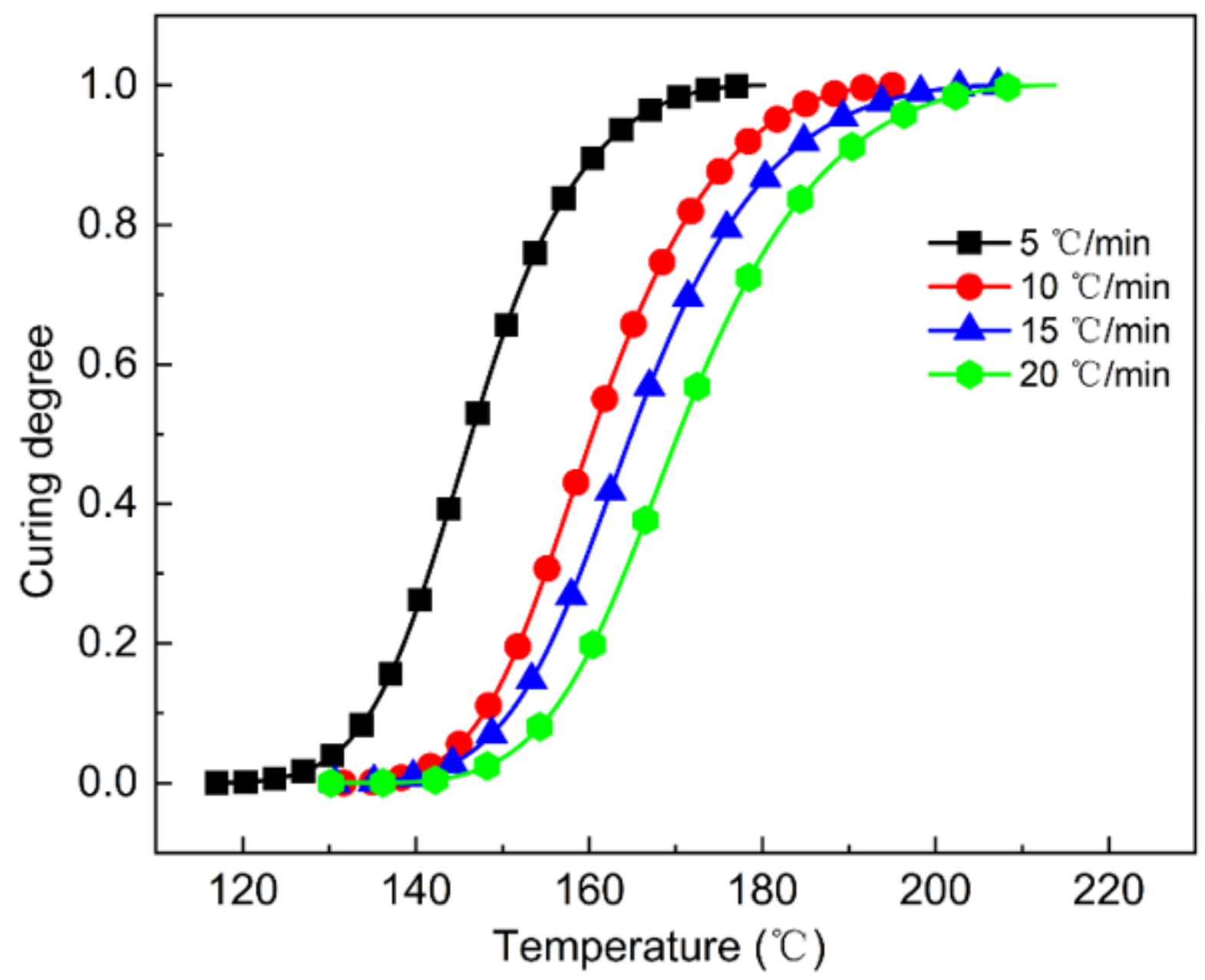

Figure 2

Curves of curing degree-temperatures 


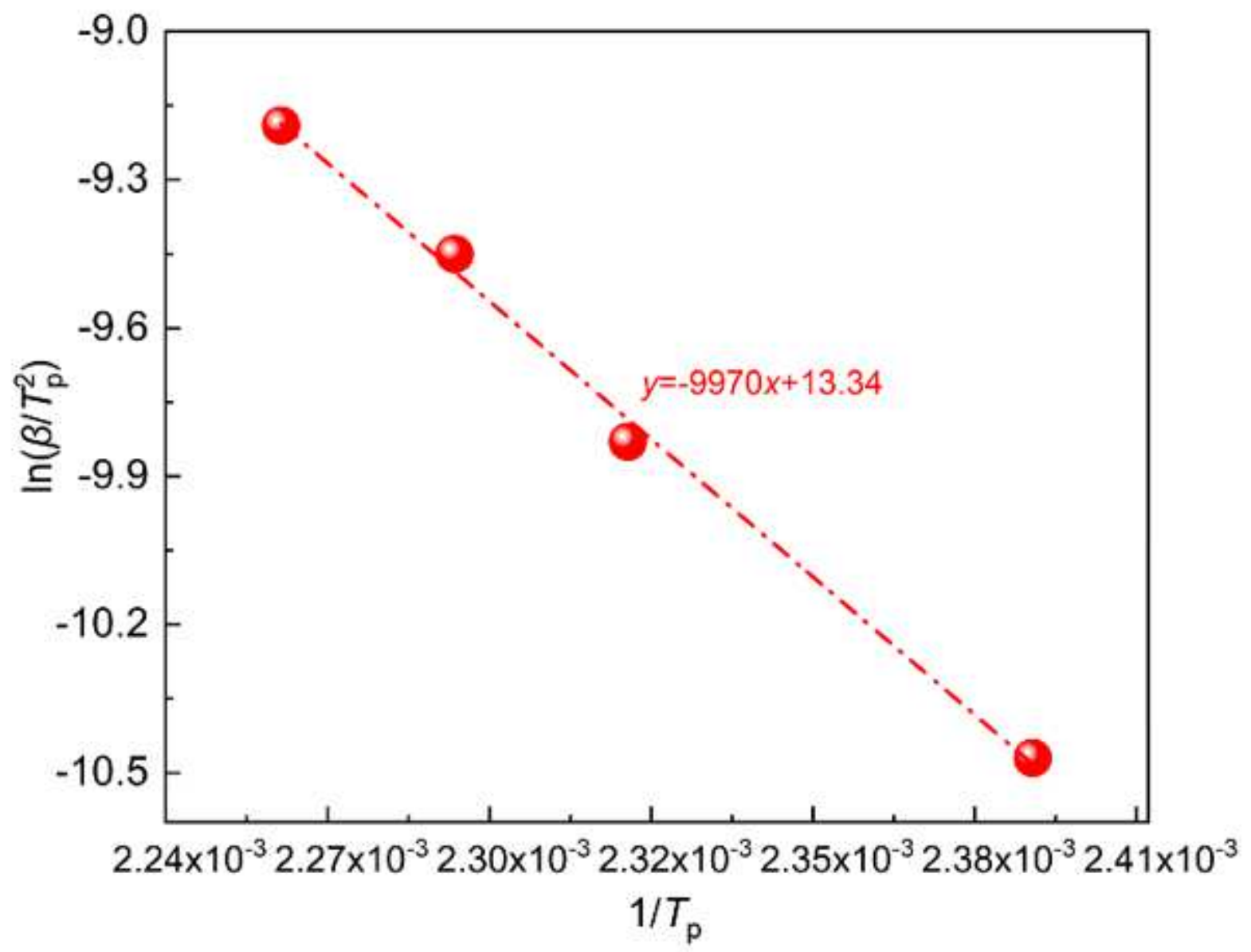

Figure 3

Fitting curve of the apparent activation energy and pre-exponential factor 


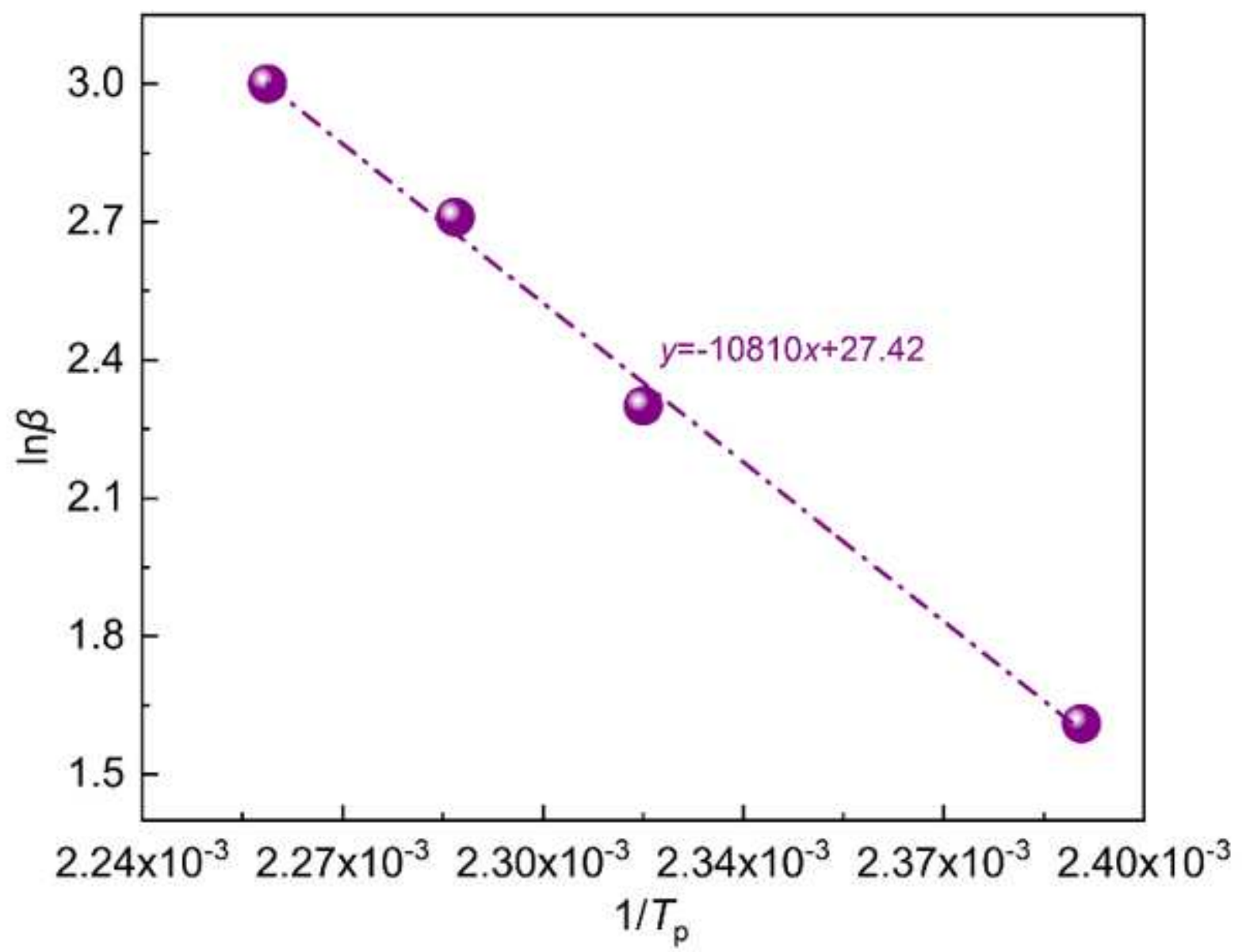

Figure 4

Fitting curve of the reaction order 


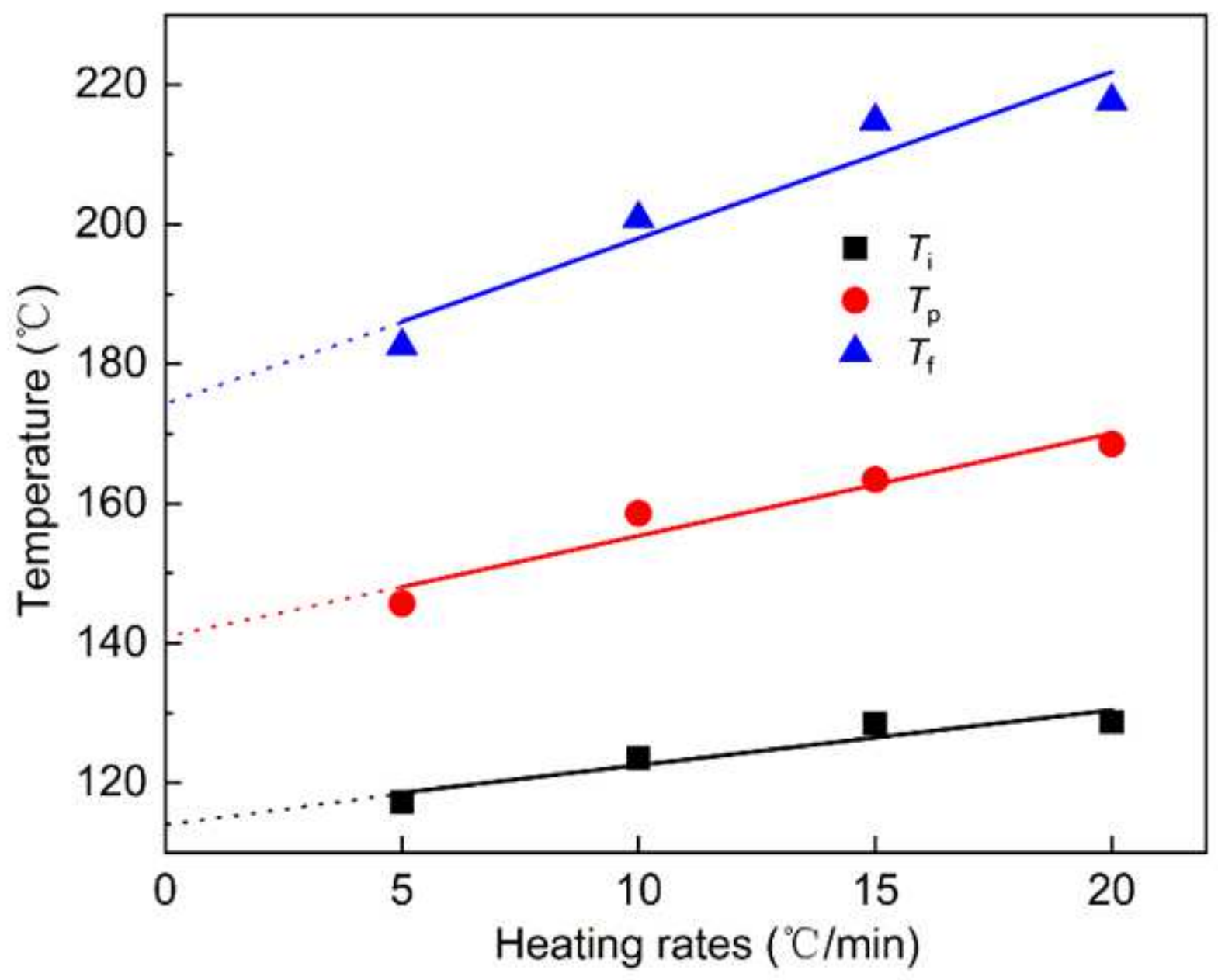

Figure 5

Extrapolation curves of the curing temperatures 


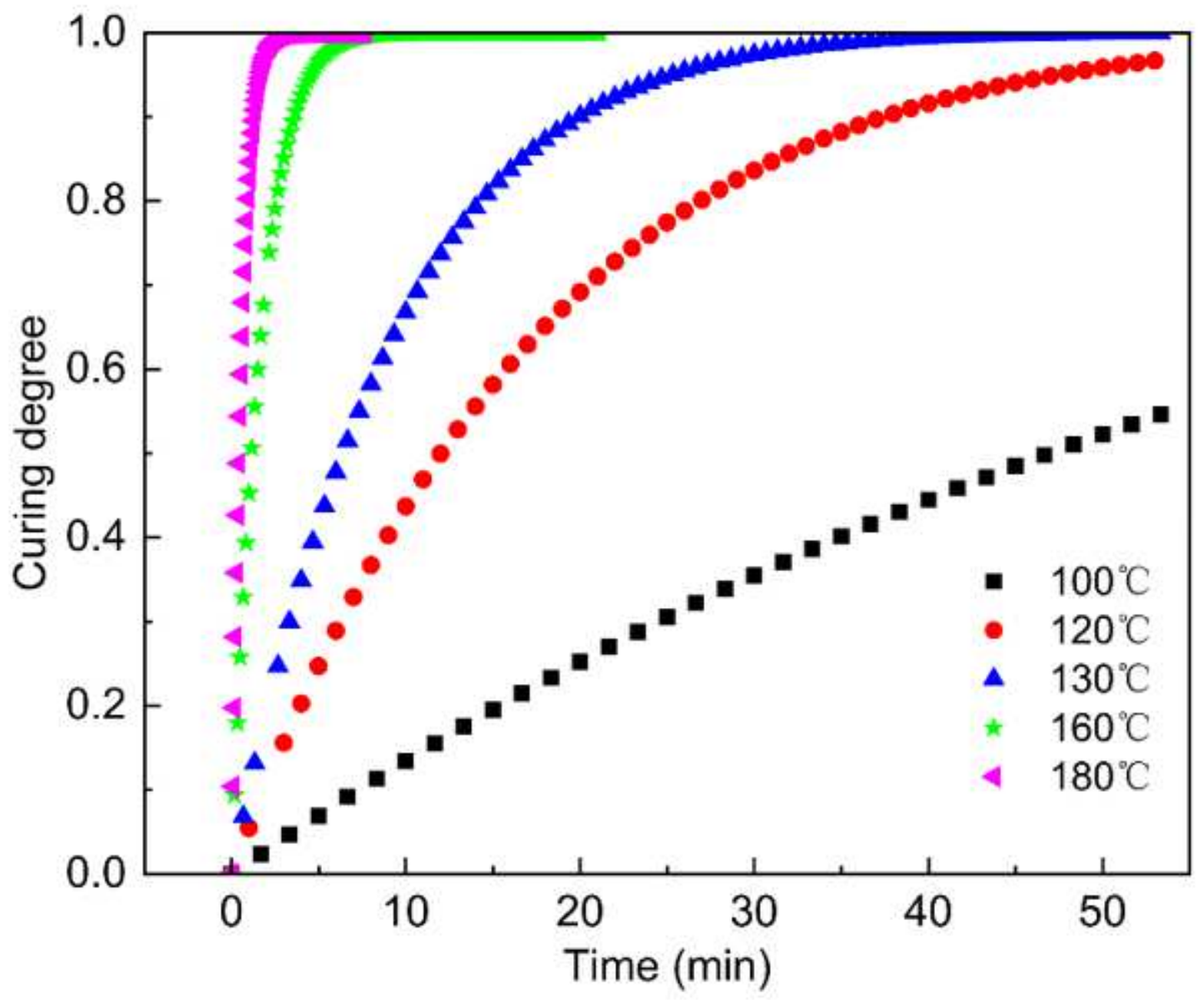

Figure 6

Curves of curing degree and time at different temperatures 


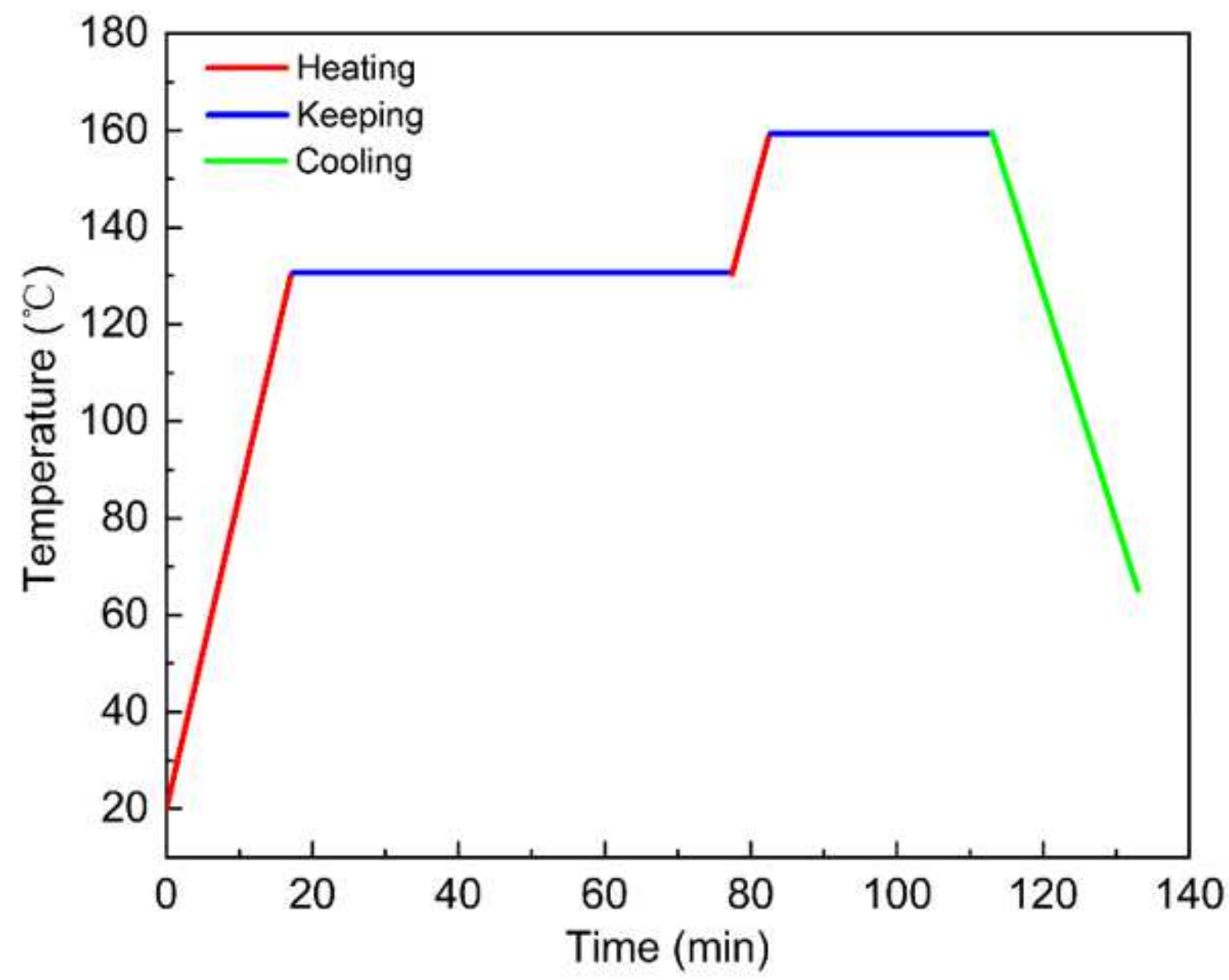

Figure 7

Curing process of the prepregs 


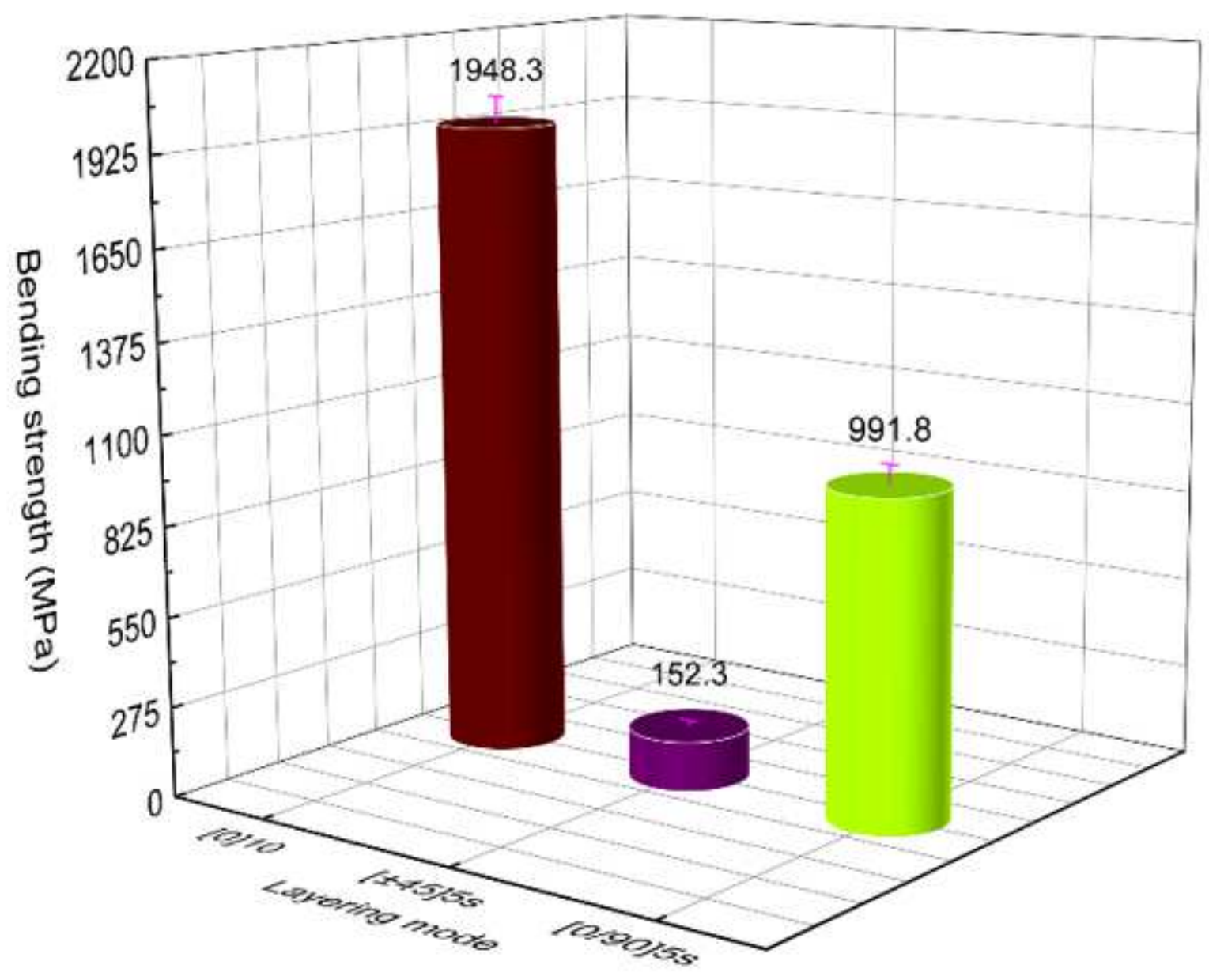

Figure 8

Bending strength of the composite laminates 


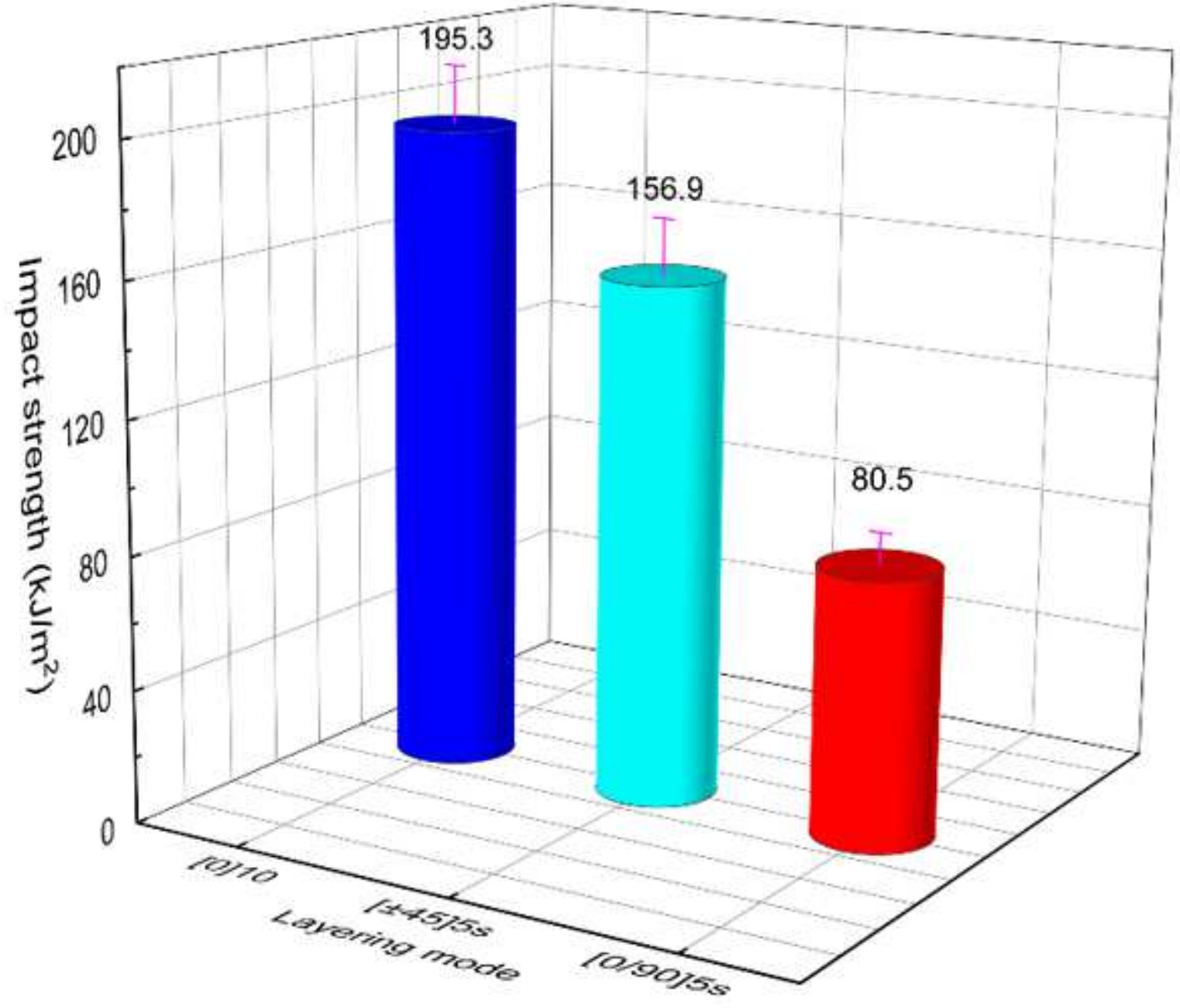

Figure 9

Impact strength of the composite laminates
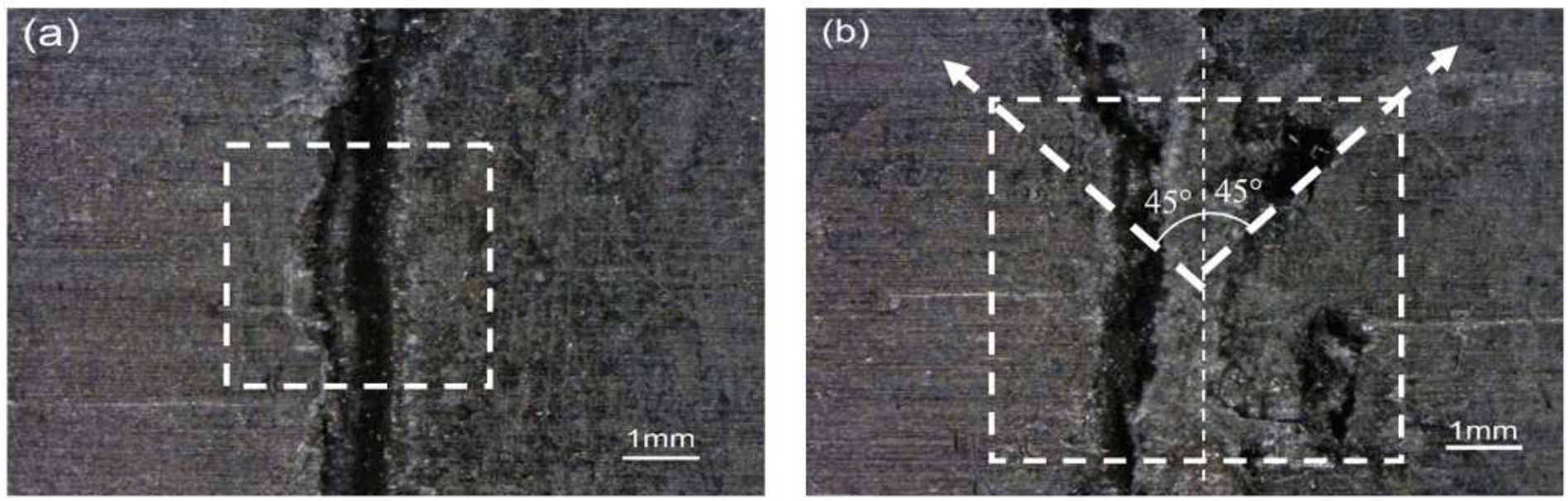

Figure 10 
Surface cracks in bending test of laminates (a) [0]10; (b) [+45/-45]5s
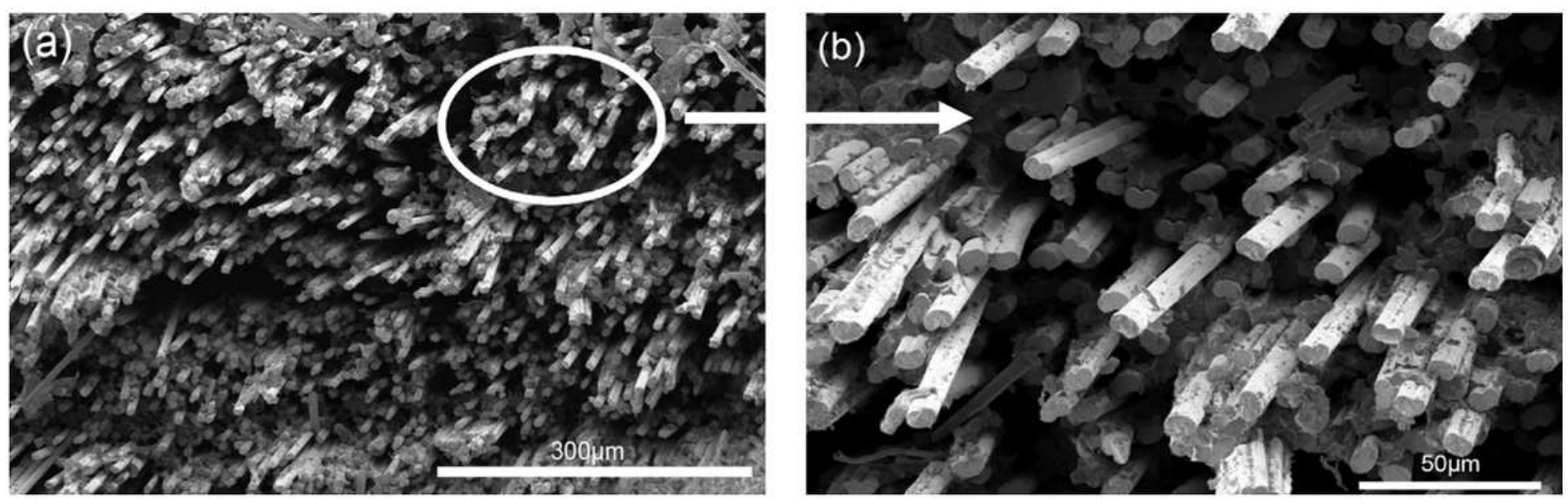

Figure 11

SEM of fractured surface in impact test of [0]10 laminate (a) 500x; (b) 2000x

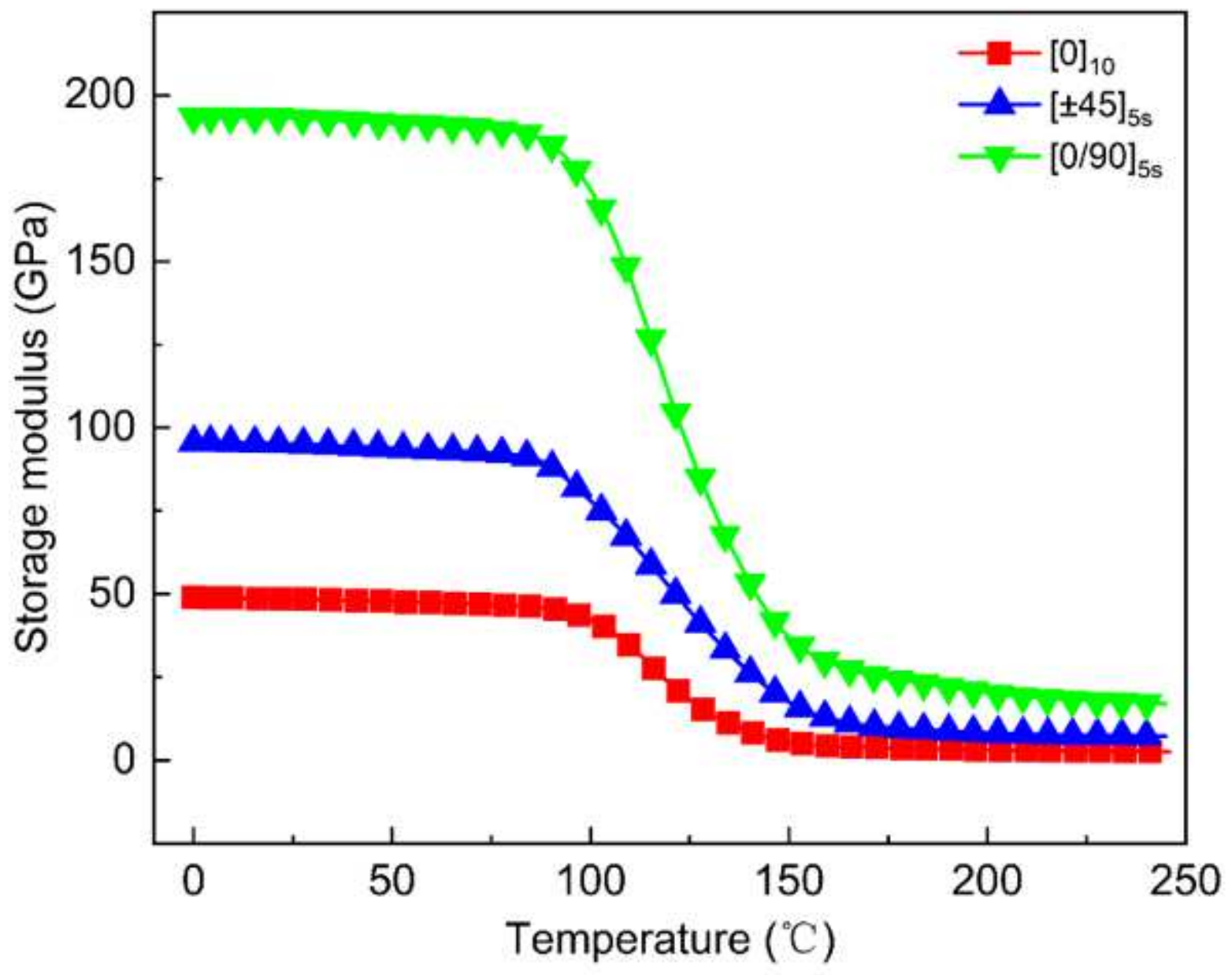

Figure 12 


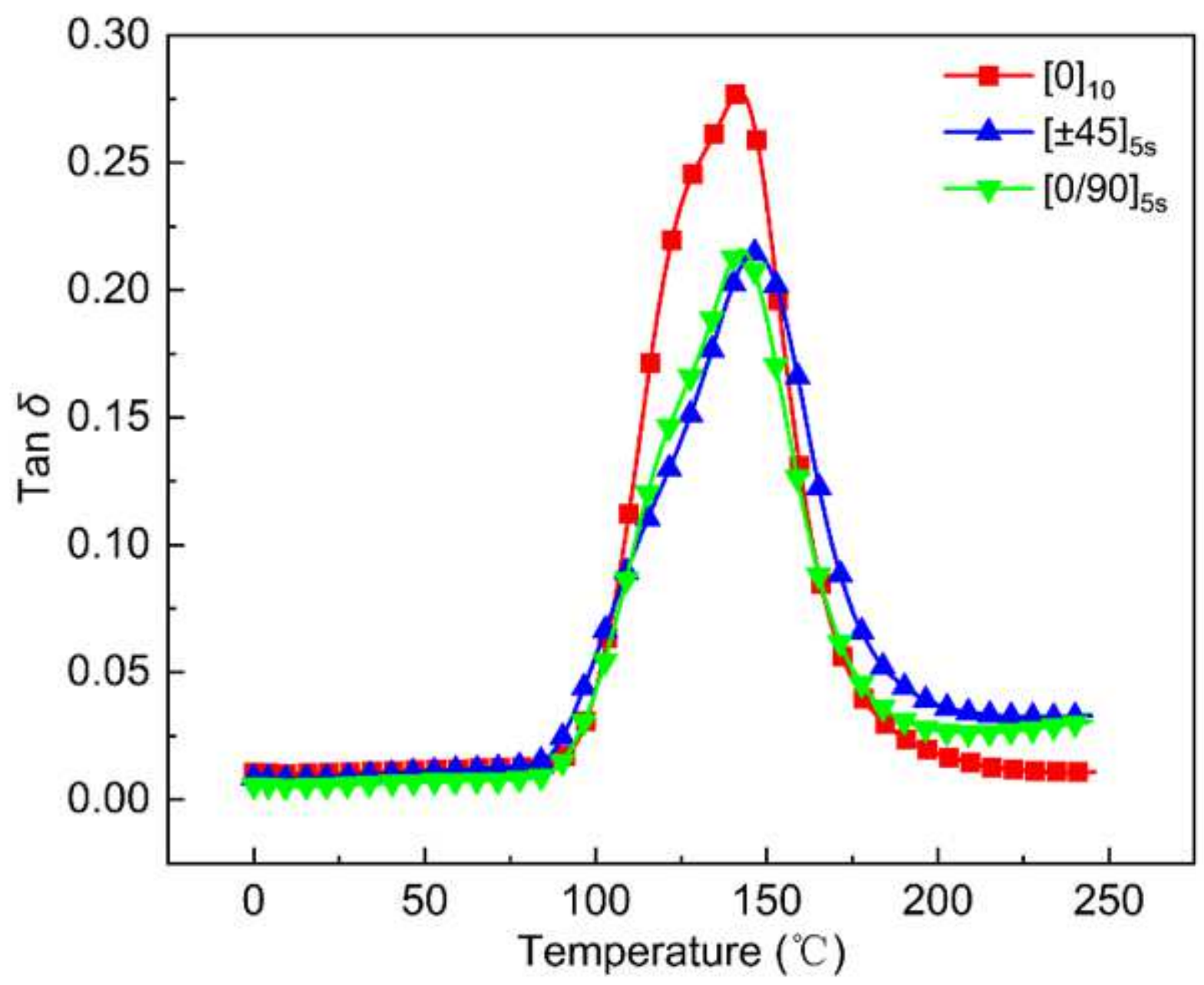

Figure 13

Loss factor curves of the laminates

\section{Supplementary Files}

This is a list of supplementary files associated with this preprint. Click to download.

- table1.docx 